\title{
Human lung adenocarcinoma cell cultures derived from malignant pleural effusions as model system to predict patients chemosensitivity
}

\author{
Giuseppe Roscilli ${ }^{1,2}$, Claudia De Vitis 1,3, Fabiana Fosca Ferrara², Alessia Noto ${ }^{1,3}$, Emanuela Cherubini', \\ Alberto Ricci ${ }^{1,4}$, Salvatore Mariotta ${ }^{1,4}$, Enrico Giarnieri ${ }^{1,4}$, Maria Rosaria Giovagnoli ${ }^{1,4}$, Maria Rosaria Torrisi ${ }^{1,4}$, \\ Francesca Bergantino ${ }^{5}$, Susan Costantini ${ }^{5}$, Francesca Fenizia ${ }^{5}$, Matilde Lambiase ${ }^{5}$, Luigi Aurisicchio ${ }^{2}$, \\ Nicola Normanno ${ }^{5}$, Gennaro Ciliberto ${ }^{5^{*}}$ and Rita Mancini ${ }^{1,3}$
}

\begin{abstract}
Background: Lung cancer is the leading cause of cancer related deaths and Malignant Pleural Effusion (MPE) is a frequent complication. Current therapies suffer from lack of efficacy in a great percentage of cases, especially when cancer is diagnosed at a late stage. Moreover patients' responses vary and the outcome is unpredictable. Therefore, the identification of patients who will benefit most of chemotherapy treatment is important for accurate prognostication and better outcome. In this study, using malignant pleural effusions (MPE) from non-small cell lung cancer (NSCLC) patients, we established a collection of patient-derived Adenocarcinoma cultures which were characterized for their sensitivity to chemotherapeutic drugs used in the clinical practice.

Methods: Tumor cells present in MPEs of patients with NSCLC were isolated by density gradient centrifugation, placed in culture and genotyped by next generation sequencing. In a subset of cases patient derived xenografts (PDX) were obtained upon tumor cell inoculation in rag2/IL2 knock-out mice. Isolated primary cultures were characterized and tested for drug sensitivity by in vitro proliferation assays. Additivity, antagonism or synergy for combinatorial treatments were determined by analysis with the Calcusyn software.

Results: We have optimized isolation procedures and culture conditions to expand in vitro primary cultures from Malignant Pleural Effusions (MPEs) of patients affected by lung adenocarcinomas, the most frequent form of non small cell lung cancer. Using this approach we have been able to establish 16 primary cultures from MPEs. Cells were banked at low passages and were characterized for their mutational pattern by next generation sequencing for most common driver mutations in lung cancer. Moreover, amplified cultures were shown to engraft with high efficiency when injected in immunocompromised mice. Cancer cell sensitivity to drugs used in standard chemotherapy regimens was assessed either individually or in combination. Differential chemosensitivity and different mutation profiles were observed which suggests that this isolation method could provide a platform for predicting the efficacy of chemotherapy in the clinical setting. Most importantly for six patients it was possible to establish a correlation between drug response in vitro and response to therapy in the clinic.
\end{abstract}

Conclusions: Results obtained using primary cultured cells from MPEs underscore the heterogeneity of NSCLC in advanced stage as indicated by drug response and mutation profile. Comparison of data obtained from in vitro

\footnotetext{
*Correspondence: g.ciliberto@istitutotumori.na.it

${ }^{5}$ IRCCS Istituto Nazionale Tumori, Fondazione "G. Pascale", Naples, Italy

Full list of author information is available at the end of the article
} 
assays with patients' responses to therapy leads to the conclusion that this strategy may provide a potentially useful approach for evaluating individual chemosensitivity profile and tailor the therapy accordingly. Furthermore, combining MPE-derived primary cultures with their genomic testing allows to identify patients eligible to trials with novel targeted agents.

Keywords: Malignant pleural effusions, NSCLC primary cultures, PDX, Next generation sequencing, In vitro chemosensitivity

\section{Background}

Lung cancer is the leading cause of cancer-related death around the world. Non-small cell lung cancer (NSCLC) comprises about $80 \%$ of all lung malignancies. More than half of NSCLC patients are diagnosed when tumor is at a late stage (III B and IV) and the only option is systemic chemotherapy [1, 2]. However, 5-year survival rate of these patients remains below $10 \%$. This low survival rate is due in large part to heterogeneity of tumor response to chemotherapy and lack of biomarkers or assays to guide the choice of the best chemotherapy. Ideally to be most effective therapy should be designed after careful assessment of the in vitro and/or in vivo chemosensitivity of patient's tumor cells against a repertoire of potential therapeutic agents in order to select the best option for each patient on a personalized basis [3-6]. Furthermore, our increasing knowledge of the complex repertoire of actionable mutations occurring in genes driving uncontrolled tumor cell growth, combined with the development of efficient and low cost next generation sequencing technologies open up new opportunities for therapeutic intervention to be exploited in the future by genomic driven clinical trials [7].

Although pursued for many years, the translation of in vitro assay-informed therapy in clinical practice has been hampered by various technical problems, including the requirement of a high technical skill level, the large number of required tumor cells, and the long turnaround time $[8,9]$. Consequently, treatment schedules and agents used in monotherapy or combination chemotherapy are still determined on the basis of the result of large clinical trials which do not take into account interpatient heterogeneity in response to chemodrugs. Hence, no reliable method has been developed to efficiently determine the best chemotherapy on an individualized basis.

The propagation of patients' tumor cells is considered to be a source of material most closely related to the original tumor. In recent years great emphasis has been given to the possibility to transplant and propagate human tumors through serial passages in immunodeficient mice devoid of B, T and NK cells [10-12]. These patient derived xenografts (PDX) have been shown to be predictive of clinical outcome compared to conventional, cell line derived xenograft (CDX) models, in particular when therapeutic compounds were tested at clinically relevant doses (CRDs) [10, 13-18]. However, engraftment and tumor growth rates usually do not allow to assess in a timely manner patients' chemosensitivity in order to instruct therapeutic decisions. PDX tumors are usually obtained from biopsies or resected primary tumors but this material is often of limited availability or cellular vitality, is not adequately preserved, and this accounts for the low engraftment rates observed in literature [19-21]. Moreover, tumor cells from sites other than the primary tumor, may increase our understanding of tumor evolution or tumor characteristics [22]. Therefore alternative sources of tumor cells are highly desirable in order to obtain sufficient material for chemosensitivity studies.

We have previously shown that tumor cells from pleural effusions of patients with NSCLC can be readily isolated and expanded in culture with high efficiency [23]. MPE is manifesting as a metastatic lesion and an advanced disease setting with poor prognosis. We showed that MPEderived cell cultures achieve efficient tumor engraftment in recipient NOD/SCID mice, also upon inoculation of small number of cells, thus suggesting indirectly the presence of tumor initiating cells. Furthermore these cells were shown to be a promising system for the study of epithelialto-mesenchimal transition (EMT) [24] and of the mechanisms responsible for resistance to EGFR inhibitors [25].

In the present study, we have analyzed a panel of low passages MPE-derived tumor cultures from NSCLC patients for a series of parameters including genetic alterations, rate of cell growth and chemosensitivity to chemotherapeutic agents currently used for the therapy of lung cancer in vitro. A subset of cultures was used to derive PDX models. Finally we tried to assess whether in vitro chemosensitivity to drugs may correlate with clinical responses. Our data, although limited to a small number of cases, suggest that MPE-derived tumor cultures could serve as a valuable tool for screening for sensitivity to chemotherapeutic agents and for genetic profiling useful to select the most effective therapy regimen.

\section{Methods \\ Patients}

A total of 16 patients (10 males and 6 females; mean age $72+7$ years; clinical stage was determined according to 
the TNM classification) with histologically or cytologically confirmed diagnosis of adenocarcinoma of the lung complicated with malignant pleural effusion were studied. Therefore, all the patients were considered to be with a stage IV of disease. Tumor specimens were obtained for diagnosis or therapeutic indications. The study was approved by S. Andrea Hospital Ethics Committee 2010 (504/10) and all patients agreed to participate to the study signing an informed consent form.

\section{MPE primary cultures}

Primary cultures were obtained as previously described [23]. Briefly, pleural fluids $(200-1000 \mathrm{ml})$ were obtained by thoracentesis and collected aseptically in heparinized $(10 \mathrm{U} / \mathrm{ml})$ bottles/tubes. Samples were centrifuged at $300 \mathrm{~g}$ for $10 \mathrm{~min}$, at $4{ }^{\circ} \mathrm{C}$, and cell pellet was resuspended in $10 \%$ FCS-RPMI (Invitrogen) or $1 \%$ BSA/2 mM EDTA/ PBS. Viability was determined by Trypan Blue exclusion dye and cell suspension was sedimented on Oncoquick (Greiner Bio One) gradient or Ficoll PLUS after the addition of RosetteSep cocktail (Stemcell). During the centrifugation step the cells were separated according to their different buoyant densities. The denser fluid components such as erythrocytes and leucocytes migrate into the lower phase through the bottom of the tube. The less dense cell fraction, including tumor cells, were enriched at the interphase layer formed between the plasma and the separation medium in the phase. After a harvesting and washing step, tumor cells were cultured in $10 \%$ FCSRPMI to obtain primary adherent cultures.

\section{Multiple gene mutation analysis by next generation sequencing}

Tumor samples were analyzed with the Ion AmpliseqTM Colon and Lung Cancer Panel (Life Technologies) using Ion Torrent semiconductor sequencing as previously described [26].

\section{Whole exome sequencing}

Next generation sequencing experiments, including quality control samples, were performed by Genomix4life S.R.L. (Baronissi, Salerno, Italy). Indexed libraries were prepared from $250 \mathrm{ng} /$ ea DNA, after sharing with a Bioruptor sonicator, using the SureSelect Human All Exon kit (50 Mb; Agilent Technologies) according to the manufacturer's instructions. Libraries were quantified using the Agilent 2100 Bioanalyzer (Agilent Technologies) and pooled in equimolar amounts to final concentration of $2 \mathrm{nM}$. Pooled samples were then subjected to cluster generation and sequencing using an Illumina HiSeq 2500 System (Illumina) in a 100 bp paired-end format at a final concentration of $8 \mathrm{pmol}$. The raw sequence files generated in fastq format underwent quality control analysis using FastQC (http://www.bioinformatics.babraham.ac.uk/projects/fastqc/).

The sequence reads were mapped against human genome (Homo sapiens Ensembl GRCh37, hg19) using Burrows-Wheeler Alignment (BWA version 0.7.7) software [27]. Sequence variations were detected by The Genome Analysis Toolkit (GATK; Broad Institute, Cambridge, MA, USA) software [28].

The Database for Annotation, Visualization and Integrated Discovery (DAVID; http://david.abcc.ncifcrf.gov) was used to perform functional annotation analysis of enriched gene ontology (GO) terms and KEGG pathways. Statistical significance was evaluated with a modified Fisher's exact test (EASE score) and GO BIOCARTA and KEGG terms with $P$ values $\leq 0.05$ were considered significant.

\section{Chemicals and reagents}

Cisplatin, carboplatin, docetaxel, vinorelbine, gemcitabine, gefitinib and erlotinib were obtained from SellekChem.

\section{Cytotoxicity assays}

To determine effects on proliferation, MPE primary cultures were treated in triplicate with increasing concentrations of anticancer drugs for $72 \mathrm{~h}$. Inhibition of cell proliferation was measured by colorimetric WST-1 assay. MPE primary cultures were plated in triplicate in 96-well flat-bottom plates at a density of 2000 cells/well and incubated overnight. Anticancer drugs were added at various concentrations in triplicates to the media and cells were cultured for an additional $72 \mathrm{~h}$. At the end of the experiment, cell survival was determined by WST-1 assay (Roche) according to the manufacturer's instructions. Absorbance was measured by spectrophotometer at a wavelength of $450 \mathrm{~nm}$ and viability was determined as percent of control cells (cells treated with the vehicle alone were defined as $100 \%$ viable). Viability data were used to calculate EC50, concentration of agent at which the cell growth is inhibited by $50 \%$. EC50 values were determined by GraphPad (prism) and data points are presented as the average value \pm the standard deviation (SD).

\section{Evaluation of drug combinations}

To determine if the antitumor effects obtained with different drug combinations were synergistic, we calculated the combination index (CI) according to the Chou-Talalay method using Calcusyn software (Biosoft, Cambridge, $\mathrm{UK})$. (CI> 1 , antagonism; $\mathrm{CI}=1$, additive effect; $\mathrm{CI}<1$, synergism). Since the Chou-Talalay model calls for cytotoxic agents to be used at a fixed dose ratio, we chose to use drug combination at equipotent ratio (ratio of EC50). 
Cells were treated with a combination that is four- to eightfold higher than the EC50, and used 1:3 serial dilutions of the highest concentration combination to generate the dose-response curve, in parallel each single agent in the combination was tested alone in the same manner. Cells were treated for $72 \mathrm{~h}$ and at the end of the experiment, cell survival was determined by WST-1 assay (Roche) according to the manufacturer's instructions.

\section{Tumor engraftment studies}

All studies have been performed in accordance with "Directive 2010/63/EU on the protection of Animals used for scientific purposes" and made effective in Italy by the Legislative Decree DLGS 26/2014. 6- to 8-weeks old Rag2/II2rg Double Knockout (Taconic) were utilized. After 1 week of acclimation they were housed five to a plastic cage and fed on basal diet (4RF24, Mucedola S.r.l.) with water ad libitum, in an animal facility controlled at a temperature of $23 \pm 2{ }^{\circ} \mathrm{C}, 60 \pm 5 \%$ humidity, and with a $12 \mathrm{~h}$ light and dark cycle. All animal protocols used for this study were reviewed and approved by the Animal Welfare Body Takis/Plaisant. Animals were euthanized by cervical dislocation at the end of the study or when severe signs of suffering were observed. Before injection, cells were washed once in PBS and their pellet was resuspended in $50 \%$ RGF matrigel (BD Biosciences) solution in Medium 199 and injected in the right flank of the mice in $200 \mu \mathrm{l}$ volume/mouse. $1 \times 106$ or $5 \times 106$ cells/mouse were injected for a total of 4-5 mice/primary culture. Tumor growth was monitored weekly by caliper measurement and tumor volume was determined by the formula $(D \times d 2) / 2$, where $D$ was the longest diameter of the tumor. The tumor doubling time (DT) in days was estimated from the log linear tumor growth during the exponential phase (range, $100-1000 \mathrm{~mm}^{3}$ ).

\section{Results and Discussion}

Mutational analysis of MPE derived cultures reveals a high degree of heterogeneity

We established sixteen MPE-derived cultures, each one from sixteen different patients affected by adenocarcinoma (AdenoCa) of the lung. In order to minimize adaptation in cell culture that may lead to selection of cell subpopulations with particular growth advantage we tried to work in the majority of cases with early passage cultures from $\mathrm{p} 2$ to p7. Exceptions were PE d/10, PE e/10 and $\mathrm{PE} \mathrm{o} / 11$ for which the earliest passage available for this study was p10. DNA was extracted as described in the methods section and subjected to Next Generation Sequencing (NGS) using the Ion AmpliseqTM Colon and Lung Cancer Panel (Life Technologies) targeting 500 hotspot regions in 22 known driver genes in lung cancer. The results reported in Table 1 show as expected a highly heterogeneous pattern of mutations which reproduces the known high degree of heterogeneity of AdenoCa of the lung [29].

Interestingly, in our small sample we observed in several cases a mutation frequency similar to that reported by TCGA, namely KRAS $37.5 \%$ vs 32.2 ; BRAF mutations 6 vs $6 \%$; MET 6 vs $4.3 \%$. TP53 mutations were unexpectedly low (18.75 vs $40 \%)$. KRAS and EGFR mutations never occurred in the same samples. Activating EGFR mutations were detected in $31 \%$ of cases vs $11.3 \%$ in TCGA. This is in line with previous reports that showed an increased frequency of EGFR mutation in malignant pleural effusions vs tumor tissue [30]. Importantly in 3 out of 5 cases of activating EGFR mutations (all Exon 19 deletions) we observed the simultaneous presence of the gatekeeper T790 M mutation which confers resistance to TKIs although none of these patients was previously treated with EGFR TKIs. The presence of a pre-existing gatekeeper T790 M mutation together with activating EGFR mutations has already been reported at variable frequency depending upon the DNA sequencing methodology and has been shown to affect time to disease progression after TKI therapy when mutation frequency is above $3 \%$ as in our cases (see Table 1) [31, 32]. Finally, we also observed a high rate $(12.5 \%)$ of mutations in the tumor suppressor STK11 gene.

In several cases mutations were detected at low frequencies (between 10 and $20 \%$ and in any case significantly below $50 \%$ ), which suggests the existence of a heterogeneous populations of cells. This has been reported before in colorectal cancer [33, 34], breast cancer [35], and lung cancer [36, 37].

Overall, using this small panel of 22 genes it was possible to identify actionable mutations in driver genes in a large proportion of cases. This may provide new therapeutic options for this type of patients if this information is used to conduct genomic driven trials with new targeted agents.

We also determined the EC50 values for EGFR TKIs gefitinib and erlotinib for all 16 cell cultures (Fig. 1). The relative pattern of sensitivity was similar but not identical. The vast majority of cultures showed an intermediate to high degree of resistance to these drugs, also in the presence of EGFR sensitizing mutations, with the only exception of $r / 11$ (one of the two cultures bearing the presence of the Exon19 deletion in EGFR without the coexistence of the resistance mutation T790 M) which showed a good sensitivity to both gefitinib and erlotinib. However, the other culture with the same NGS mutational pattern, namely v/11 was highly resistant to both drugs, which suggests that chemosensitivity may be affected by other mutational or epigenetic changes not revealed by this analysis. The three cultures 
Table 1 Mutations identified in MPE primary cultures

\begin{tabular}{|c|c|c|c|c|c|c|c|c|c|}
\hline & \multirow[t]{2}{*}{ KRAS } & \multicolumn{2}{|l|}{ EGFR } & \multirow[t]{2}{*}{ PIK3CA } & \multirow[t]{2}{*}{ BRAF } & \multirow[t]{2}{*}{ MET } & \multirow[t]{2}{*}{ TP53 } & \multirow[t]{2}{*}{ STK11 } & \multirow[t]{2}{*}{ In vivo } \\
\hline & & Exon19del & T790 M & & & & & & \\
\hline $\begin{array}{l}\mathrm{PE} \mathrm{d} / 10 \\
(\mathrm{p} 10)\end{array}$ & $\begin{array}{l}46 \% \\
\text { p.G12V } \\
\text { (c. } 35 \mathrm{G}>\mathrm{T})\end{array}$ & & & & & & & & No \\
\hline $\begin{array}{l}\mathrm{PE} e / 10 \\
\text { (p10) }\end{array}$ & $\begin{array}{l}87.9 \% \\
\text { p.Q61H } \\
\text { (c.183 A>C) }\end{array}$ & & & & & $\begin{array}{l}31.6 \% \\
\text { p. } T 10101 \\
\text { (c. } 3029 \text { C>T) }\end{array}$ & & & Yes \\
\hline $\begin{array}{l}\mathrm{PE} b / 11 \\
\text { (p3) }\end{array}$ & & & & & $\begin{array}{l}53.5 \% \\
\text { p.V600E } \\
\text { (c.1799T>A) }\end{array}$ & & & & Yes \\
\hline $\begin{array}{l}\mathrm{PE} g / 11 \\
\text { (p6) }\end{array}$ & & & & & & & & & Yes \\
\hline $\begin{array}{l}P E h / 11 \\
\text { (p4) }\end{array}$ & $\begin{array}{l}43.1 \% \\
\text { p.G12D } \\
\text { (c. } 35 \mathrm{G}>\mathrm{A})\end{array}$ & & & & & & & & No \\
\hline $\begin{array}{l}\text { PE i/11 } \\
\text { (p5) }\end{array}$ & $\begin{array}{l}37.2 \% \\
\text { p.Q61 K } \\
(c .181 C>A)\end{array}$ & & & & & & $\begin{array}{l}100 \% \\
\text { p.R175H } \\
\text { (c.524 G>A) }\end{array}$ & & Yes \\
\hline $\begin{array}{l}\mathrm{PE} n / 11 \\
\text { (p3) }\end{array}$ & & & & & & & & & Yes \\
\hline $\begin{array}{l}\mathrm{PE} O / 11 \\
\text { (p10) }\end{array}$ & $\begin{array}{l}98.8 \% \\
\text { p.Q61H } \\
\text { (c.183 A>T) }\end{array}$ & & & $\begin{array}{l}54.2 \% \\
\text { p.E545 K } \\
\text { (c.1633 G>A) }\end{array}$ & & & & $\begin{array}{l}100 \% \\
\text { p.Q37* } \\
\text { (c.109 C>T) }\end{array}$ & No \\
\hline $\begin{array}{l}\mathrm{PE} p / 11 \\
(\mathrm{p} 7)\end{array}$ & & $\begin{array}{l}100 \% \\
\text { p.E746_A750del } \\
\text { (c.2235_2249del15) }\end{array}$ & $\begin{array}{l}17.2 \% \\
\text { p.T790 M } \\
\text { (c.2369 C>T) }\end{array}$ & & & & $\begin{array}{l}100 \% \\
\text { p.R248Q } \\
\text { (c.743 G>A) }\end{array}$ & & No \\
\hline $\begin{array}{l}\mathrm{PE} \mathrm{r} / 11 \\
\text { (p5) }\end{array}$ & & $\begin{array}{l}47 \% \\
\text { p.E746_A750del } \\
\text { (c.2235_2249del15) }\end{array}$ & & & & & & & No \\
\hline $\begin{array}{l}\text { PE s/11 } \\
\text { (p3) }\end{array}$ & & $\begin{array}{l}42 \% \\
\text { p.E746_A750del } \\
\text { (c.2235_2249del15) }\end{array}$ & $\begin{array}{l}15 \% \\
\text { p.T790 M } \\
\text { (c.2369 C>T) }\end{array}$ & & & & $\begin{array}{l}14.3 \% \\
\text { p.S241F } \\
\text { (c.722 C>T) }\end{array}$ & & Yes \\
\hline $\begin{array}{l}\mathrm{PE} \mathrm{u/11} \\
(\mathrm{p} 6)\end{array}$ & & $\begin{array}{l}49 \% \\
\text { p.E746_A750del } \\
\text { (c.2235_2249del15) }\end{array}$ & $\begin{array}{l}11.3 \% \\
\text { p.T790 M } \\
\text { (c.2369 C>T) }\end{array}$ & & & & & & Yes \\
\hline $\begin{array}{l}\mathrm{PE} \vee / 11 \\
(\mathrm{p} 2)\end{array}$ & & $\begin{array}{l}57 \% \\
\text { p.E746_A750del } \\
\text { (c.2235_2249del15) }\end{array}$ & & & & & & & Yes \\
\hline $\begin{array}{l}\mathrm{PE} z / 11 \\
\text { (p4) }\end{array}$ & & & & & & & & & Yes \\
\hline $\begin{array}{l}\mathrm{PE} b / 12 \\
\text { (p4) }\end{array}$ & $\begin{array}{l}100 \% \\
\text { p.Q61H } \\
\text { (c.183 A>C) }\end{array}$ & & & $\begin{array}{l}49.1 \% \\
\text { p.E545 K } \\
\text { (c. } 1633 \mathrm{G}>\mathrm{A} \text { ) }\end{array}$ & & & & $\begin{array}{l}100 \% \\
\text { p.Q37* } \\
\text { (c.109 C>T) }\end{array}$ & Yes \\
\hline $\begin{array}{l}P E \text { f/13 } \\
\text { (p3) }\end{array}$ & & & & & & & & & No \\
\hline
\end{tabular}

with coexisting Exon19 deletion and T790 M mutations, $\mathrm{p} / 11, \mathrm{~s} / 11$ and $\mathrm{u} / 11$, were as expected intermediate to highly resistant to both drugs. Overall however, the NGS mutational pattern reported Table 1 did not allow to predict chemosensitivity to both gefitinib and erlotinib shown in Fig. 1. This was also the case for the six cultures bearing KRAS mutations $(\mathrm{d} / 10, \mathrm{e} / 10$, $\mathrm{h} / 11, \mathrm{i} / 11, \mathrm{o} / 11$ and $\mathrm{b} / 12$ ) alone or in combination with others. Although it is interesting to observe that within this group the more sensitive cultures were those bearing mutations in PIK3CA, their response to drugs spanned the entire range.

In conclusion, although we are cognizant of the small number of cases analyzed, in our system drug sensitivity to TKIs could not be entirely anticipated by NGS data. This supports two important concepts: (a) sensitivity 


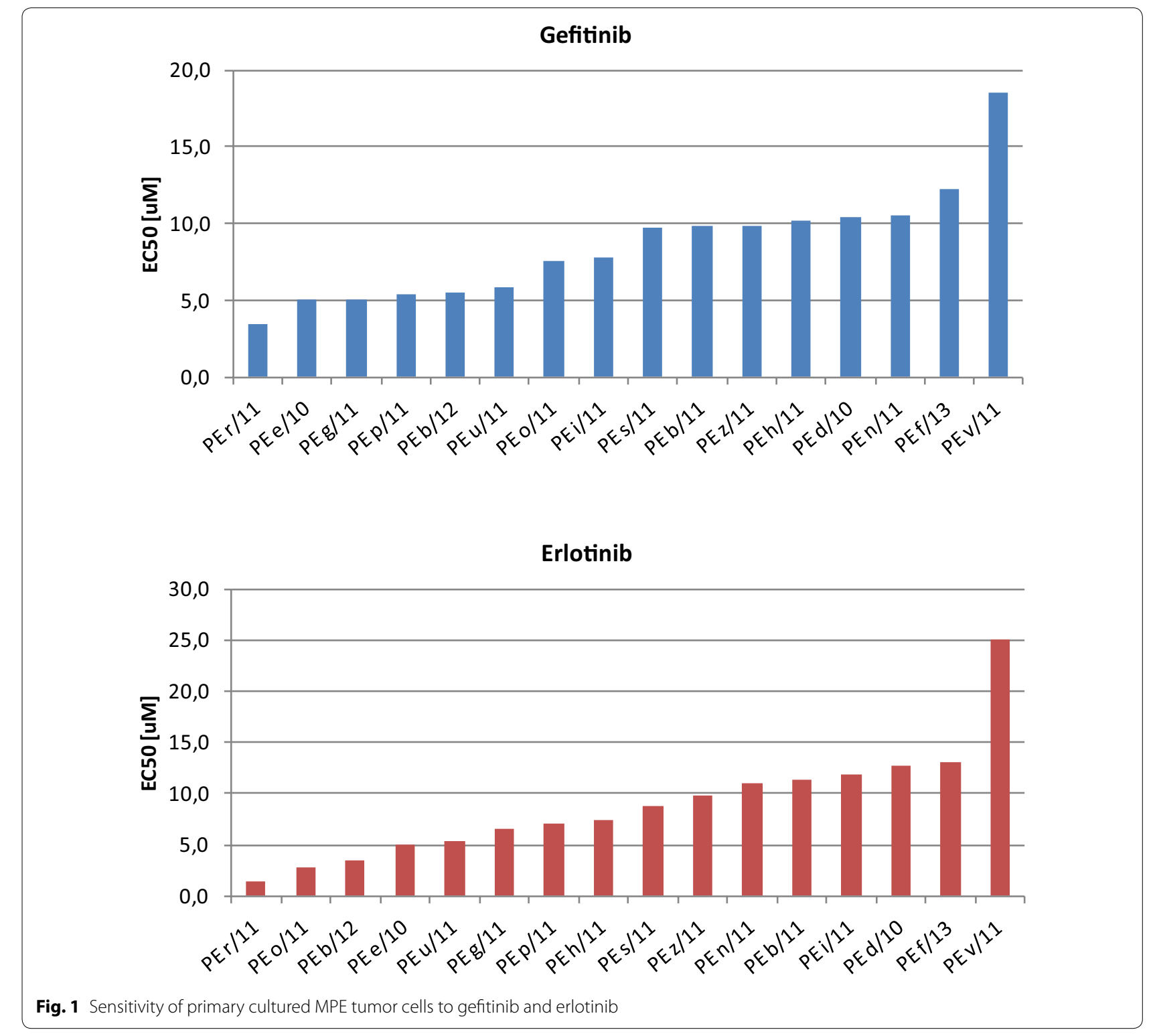

to TKIs may be strongly affected by additional genetic or epigenetic changes not revealed by our present NGS panel; (b) empirical determination of drug sensitivity is an added value to predict drug sensitivity in the clinic.

\section{Whole exome analysis reveals a pattern of mutations affecting distinct signaling and metabolic pathways}

To identify the metabolic pathways affected in MPEderived cultures, we performed whole exome sequencing on five randomly chosen samples, b/12, n/11, o/11, s/11 and $\mathrm{u} / 11$ which taken together well represent the differential degree of sensitivity to gefitinib and erlotinib. This analysis generated an average number of mappable sequence data equal to $55.19 \pm 21.40 \mathrm{~Gb}$ (Additional file 1: Table S1). A percentage higher than $99.5 \%$ of the total reads produced was mapped to the reference human coding exome (Homo sapiens Ensembl GRCh37, hg19). From this amount of data, GATK version 3.3-3 identified an average of 219,178 $\pm 57,043$ genetic variants, among which 21,220 \pm 349 exomic and splice site type and $9830 \pm 159$ non-synonymous variants. Focusing on two samples having the same mutated genes by targeted resequencing (see previous paragraph), $b / 12$ and $o / 11$, it is possible to underline that they have a total number of variants equal to 20,963 and 21,499 among which 10,214 and 10,499 non-synonymous variants respectively. Then we evaluated also the total number of shared non-synonymous variants among the five MPE-derived cultures that resulted to be 4060 in 2573 different genes. The common mutations were distributed through the whole genome 
but higher frequency were found in chromosomes 1, 11 and 19 (Additional file 2: Figure S1)

To investigate the possible biological and metabolic role of the mutated genes, we categorized them into enriched categories according to GO molecular function classification and BIOCARTA and KEGG pathway analysis.

The top GO categories that resulted significantly enriched with a $P$ value $\leq 0.05$ and that comprised a number of genes higher than 50 were: ion binding, calcium ion binding, peptidase activity, olfactory receptor activity, structural molecule activity, cytoskeletal protein binding, endopeptidase activity, carbohydrate binding and actin binding.

Moreover, to evaluate the enrichment in signaling pathways, we performed BIOCARTA and KEGG analysis on the 2573 genes. The top 6 enriched pathways in BIOCARTA database were: B Lymphocyte Cell Surface Molecules, Monocyte and its Surface Molecules, Role of BRCA1, BRCA2 and ATR in Cancer Susceptibility, Regulation of cell cycle progression by Plk3, Adhesion Molecules on Lymphocyte, and Cells and Molecules involved in local acute inflammatory response (Fig. 2a). Among the genes involved in these pathways there are CD44, some integrins, BRCA1, BRCA2 and TP53. The top 7 enriched pathways in KEGG database were: Olfactory transduction, ECM-receptor interaction, Taste transduction,

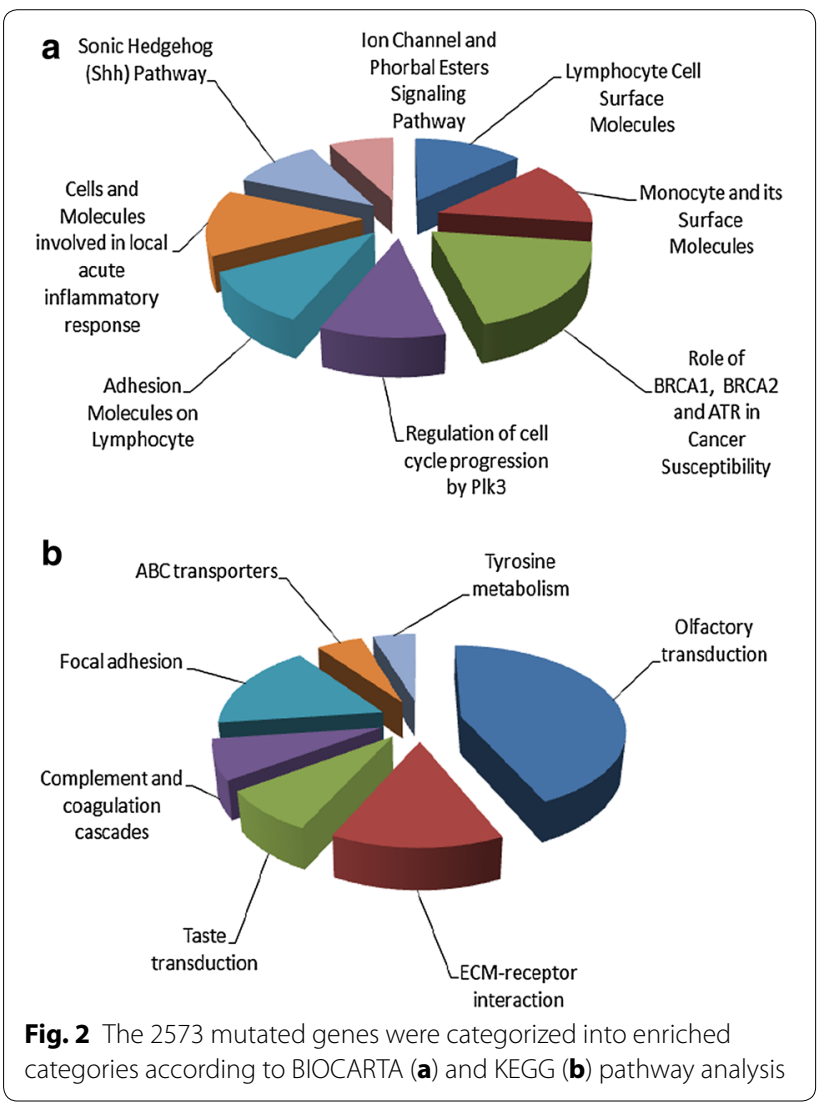

Complement and coagulation cascades, Focal adhesion, $\mathrm{ABC}$ transporters, and Tyrosine metabolism (Fig. 2b). In these different pathways we found involved the olfactory receptor family, the taste receptors, some coagulation and complement factors, a2-microglobulin, ATP-binding cassette family, alcohol dehydrogenases, collagen type family, integrins, laminins, ERBB2, protein kinase $\mathrm{C}$ and cyclin D3.

\section{In vivo tumor growth often leads to selection of cell populations with a different mutational pattern}

Malignant pleural effusion is a poor prognostic factor for patients with lung cancer and the treatment is merely palliative [38]. Patient-derived tumor xenograft (PDX) models have been established and increasingly used for preclinical studies of targeted therapies in recent years. However, PDX mouse models are difficult to obtain with low percentage of success [19] and in particular, patientderived non-small cell lung cancer (NSCLC) xenograft are relatively few in number and are limited in their degree of genetic characterization. We have characterized the isolated primary cultures for their ability to establish tumor xenograft in rag2-/Il2- double knock-out mice. Among the primary culture tested, more than $80 \%$ of them were able to grow when injected s.c. establish subcutaneous xenografts. Moreover a great variability in latency time and doubling time was observed as shown in (Additional file 1: Table S2).

We extracted gDNA from tumors grown in PDX and carried out mutational analysis with the same NGS panel used for MPE-derived cells grown in vitro and the comparison of the pattern of mutations in the same samples between in vitro and in vivo is shown in Table 2.

It can immediately be appreciated that in vivo growth causes an overall increase in the frequency of mutations. Out of the 10 samples analyzed in parallel, only 3 (b/12, $\mathrm{s} / 11$ and $\mathrm{i} / 11$ ) maintain the same mutational pattern, with some differences in the abundance of cells with mutations between in vitro culture and PDX. In the remaining samples the pattern of mutations is dramatically different. In particular we can observe three major phenomena: (a) dramatic increase of TP53 mutations which now slightly exceed the frequency observed in TCGA (50 vs $40 \%$ ), (b) appearance of mutations in MPE-derived samples where no mutation had been detected in vitro $(\mathrm{g} / 11, \mathrm{n} / 11)$, (c) disappearance of mutations present in the in vitro culture at low frequency and appearance of new mutations very often at high frequency.

This finding is of relevance because it suggests that some primary cultures are intrinsically highly heterogeneous in their composition and contain at very low percentages subclones carrying mutations undetectable by NGS. A dynamic adaptation takes place in the local 
Table 2 Comparison of Mutations identified in MPE primary cultures and PDX

\begin{tabular}{|c|c|c|c|c|c|c|c|c|}
\hline & \multirow[t]{2}{*}{ KRAS } & \multicolumn{2}{|l|}{ EGFR } & \multirow[t]{2}{*}{ PIK3CA } & \multirow[t]{2}{*}{ BRAF } & \multirow[t]{2}{*}{ MET } & \multirow[t]{2}{*}{ TP53 } & \multirow[t]{2}{*}{ STK11 } \\
\hline & & Exon19del & T790 M & & & & & \\
\hline $\begin{array}{l}\mathrm{PE} e / 10 \\
\text { (p10) }\end{array}$ & $\begin{array}{l}87.9 \% \\
\text { p.Q61H } \\
(c .183 \mathrm{~A}>C)\end{array}$ & & & & & $\begin{array}{l}31.6 \% \\
\text { p. T1010l } \\
\text { (c. } 3029 \text { C>T) }\end{array}$ & & \\
\hline $\begin{array}{l}\mathrm{PE} e / 10 \\
\text { (PDX) }\end{array}$ & $\begin{array}{l}50.4 \% \\
\text { p.Q61 } \\
(\text { c.183 A>C) }\end{array}$ & & & $\begin{array}{l}49.2 \% \\
\text { p.E545 K } \\
\text { (c.1633 G>A) }\end{array}$ & & & & $\begin{array}{l}44.5 \% \\
\text { p.Q37* } \\
\text { (c.109 C>T) }\end{array}$ \\
\hline $\begin{array}{l}\mathrm{PE} b / 11 \\
\text { (p3) }\end{array}$ & & & & & $\begin{array}{l}53.5 \% \\
\text { p.V600E } \\
\text { (c.1799T>A) }\end{array}$ & & & \\
\hline $\begin{array}{l}\mathrm{PE} b / 11 \\
\text { (PDX) }\end{array}$ & & $\begin{array}{l}100 \% \\
\text { p.E746_A750del } \\
\text { (c.2235_2249del15) }\end{array}$ & $\begin{array}{l}15.2 \% \\
\text { p.T790 M } \\
\text { (c.2369 C>T) }\end{array}$ & & & & $\begin{array}{l}97.6 \% \\
\text { p.R248Q } \\
(c .743 \mathrm{G}>A)\end{array}$ & \\
\hline \multicolumn{9}{|l|}{$\begin{array}{l}\mathrm{PE} \mathrm{g} / 11 \\
\text { (p6) }\end{array}$} \\
\hline $\begin{array}{l}\mathrm{PE} \mathrm{g} / 11 \\
\text { (PDX) }\end{array}$ & $\begin{array}{l}75.5 \% \\
\text { p.Q61 } \\
(\text { c.183 A>C) }\end{array}$ & & & $\begin{array}{l}49.5 \% \\
\text { p.E545 K } \\
\text { (c.1633 G>A) }\end{array}$ & & & & $\begin{array}{l}77.7 \% \\
\text { p.Q37* } \\
\text { (c.109C>T) }\end{array}$ \\
\hline $\begin{array}{l}\text { PE i/11 } \\
\text { (p5) }\end{array}$ & $\begin{array}{l}37.2 \% \\
\text { p.Q61 K } \\
(\text { c. } 181 \mathrm{C}>\mathrm{A})\end{array}$ & & & & & & $\begin{array}{l}100 \% \\
\text { p.R175H } \\
\text { (c.524 G>A) }\end{array}$ & \\
\hline $\begin{array}{l}\mathrm{PE} \mathrm{i/11} \\
\text { (PDX) }\end{array}$ & $\begin{array}{l}29.4 \% \\
\text { p.Q61 K } \\
(\text { c.181 C>A) }\end{array}$ & & & & & & $\begin{array}{l}100 \% \\
\text { p.R175H } \\
\text { (c.524 G>A) }\end{array}$ & \\
\hline \multicolumn{9}{|c|}{ PE n/11 (p3) } \\
\hline $\begin{array}{l}\mathrm{PE} n / 11 \\
\text { (PDX) }\end{array}$ & $\begin{array}{l}27 \% \\
\text { p.Q61 K } \\
\text { (c.181 C>A) }\end{array}$ & & & & & & $\begin{array}{l}100 \% \\
\text { p.R175H } \\
\text { (c.524 G>A) }\end{array}$ & \\
\hline $\begin{array}{l}\text { PE s/11 } \\
\text { (p3) }\end{array}$ & & $\begin{array}{l}42 \% \\
\text { p.E746_A750del } \\
\text { (c.2235_2249del15) }\end{array}$ & $\begin{array}{l}15 \% \\
\text { p.T790 M } \\
\text { (c.2369 C>T) }\end{array}$ & & & & $\begin{array}{l}14.3 \% \\
\text { p.S241F } \\
(c .722 \mathrm{C}>\mathrm{T})\end{array}$ & \\
\hline $\begin{array}{l}\mathrm{PE} \mathrm{S} / 11 \\
(\mathrm{PDX})\end{array}$ & & $\begin{array}{l}100 \% \\
\text { p.E746_A750del } \\
\text { (c.2235_2249del15) }\end{array}$ & $\begin{array}{l}15.8 \% \\
\text { p.T790 M } \\
\text { (c.2369 C>T) }\end{array}$ & & & & $\begin{array}{l}94.7 \% \\
\text { p.R248Q } \\
\text { (c.743 G>A) }\end{array}$ & \\
\hline $\begin{array}{l}\mathrm{PE} \mathrm{u/11} \\
(\mathrm{p} 6)\end{array}$ & & $\begin{array}{l}49 \% \\
\text { p.E746_A750del } \\
\text { (c.2235_2249del15) }\end{array}$ & $\begin{array}{l}11.3 \% \\
\text { p.T790 M } \\
\text { (c.2369 C>T) }\end{array}$ & & & & & \\
\hline $\begin{array}{l}\mathrm{PE} \mathrm{u} / 11 \\
\text { (PDX) }\end{array}$ & & $\begin{array}{l}92 \% \\
\text { p.E746_A750del } \\
\text { (c.2235_2249del15) }\end{array}$ & $\begin{array}{l}11.8 \% \\
\text { p.T790 M } \\
\text { (c.2369 C>T) }\end{array}$ & & & & $\begin{array}{l}100 \% \\
\text { p.R248Q } \\
\text { (c.743G>A) }\end{array}$ & \\
\hline $\begin{array}{l}\text { PE v/11 } \\
\text { (p2) }\end{array}$ & & $\begin{array}{l}57 \% \\
\text { p.E746_A750del } \\
\text { (c.2235_2249del15) }\end{array}$ & & & & & & \\
\hline $\begin{array}{l}\mathrm{PE} \text { V/11 } \\
\text { (PDX) }\end{array}$ & & $\begin{array}{l}87.5 \% \\
\text { p.E746_A750del } \\
\text { (c.2235_2249del15) }\end{array}$ & & & & & $\begin{array}{l}93.5 \% \\
\text { p.R248Q } \\
(c .743 \mathrm{G}>A)\end{array}$ & \\
\hline \multicolumn{9}{|c|}{ PE z/11 (p4) } \\
\hline $\begin{array}{l}\mathrm{PE} z / 11 \\
\text { (PDX) }\end{array}$ & & $\begin{array}{l}100 \% \\
\text { p.E746_A750del } \\
\text { (c.2235_2249del15) }\end{array}$ & $\begin{array}{l}14.2 \% \\
\text { p.T790 M } \\
\text { (c.2369 C>T) }\end{array}$ & & & & $\begin{array}{l}98.8 \% \\
\text { p.R248Q } \\
(c .743 \mathrm{G}>A)\end{array}$ & \\
\hline $\begin{array}{l}\mathrm{PE} \mathrm{b} / 12 \\
\text { (p4) }\end{array}$ & $\begin{array}{l}100 \% \\
\text { p.Q61H } \\
\text { (c.183 A>C) }\end{array}$ & & & $\begin{array}{l}49.1 \% \\
\text { p.E545 K } \\
\text { (c.1633 G>A) }\end{array}$ & & & & $\begin{array}{l}100 \% \\
\text { p.Q37* } \\
\text { (c.109 C>T) }\end{array}$ \\
\hline $\begin{array}{l}\mathrm{PE} \mathrm{b} / 12 \\
\text { (PDX) }\end{array}$ & $\begin{array}{l}65.7 \% \\
\text { p.Q61H } \\
(\text { c.183 A>C) }\end{array}$ & & & $\begin{array}{l}49 \% \\
\text { p.E545 K } \\
\text { (c.1633 G>A) }\end{array}$ & & & & $\begin{array}{l}63 \% \\
\text { p.Q37* } \\
\text { (c.109 C>T) }\end{array}$ \\
\hline
\end{tabular}

* nonsense mutation 
tumor microenvironment by which these subclones emerge, while others disappear. Based on these data we believe that combining genetic testing of both primary cultures and PDX-derived tumors may provide a more complete analysis of the spectrum of tumor mutations for this group of patients.

\section{In vitro drug testing shows a high degree of differences in drug sensitivity in MPE-derived cultures}

MPE-derived primary cultures were analyzed for their sensitivity to different chemotherapeutic drugs used in conventional adenocarcinoma lung therapies, cisplatin, carboplatin, gemcitabine, vinolrebine and docetaxel.
Chemodrugs were dosed as single agents and results showed a great variability in the response obtained (Fig. 3). Among the primary cultures PE v/11, i/11, n/11 displayed cross resistance between most of the drugs tested. The majority of primary cultures was resistant to cisplatin (10 out of 16 of them showed an EC50 higher than $20 \mu \mathrm{M}$ ), while we observed a greater degree of sensitivity to carboplatin (only 5 out of 18 had an EC50 higher than $20 \mu \mathrm{M})$. Carboplatin is a second generation platinum based compound with a different toxicity profile than cisplatin. Apart from the toxicity profile, the two compounds have a very similar mechanism of action, inducing the same type of DNA-platinum adducts, and

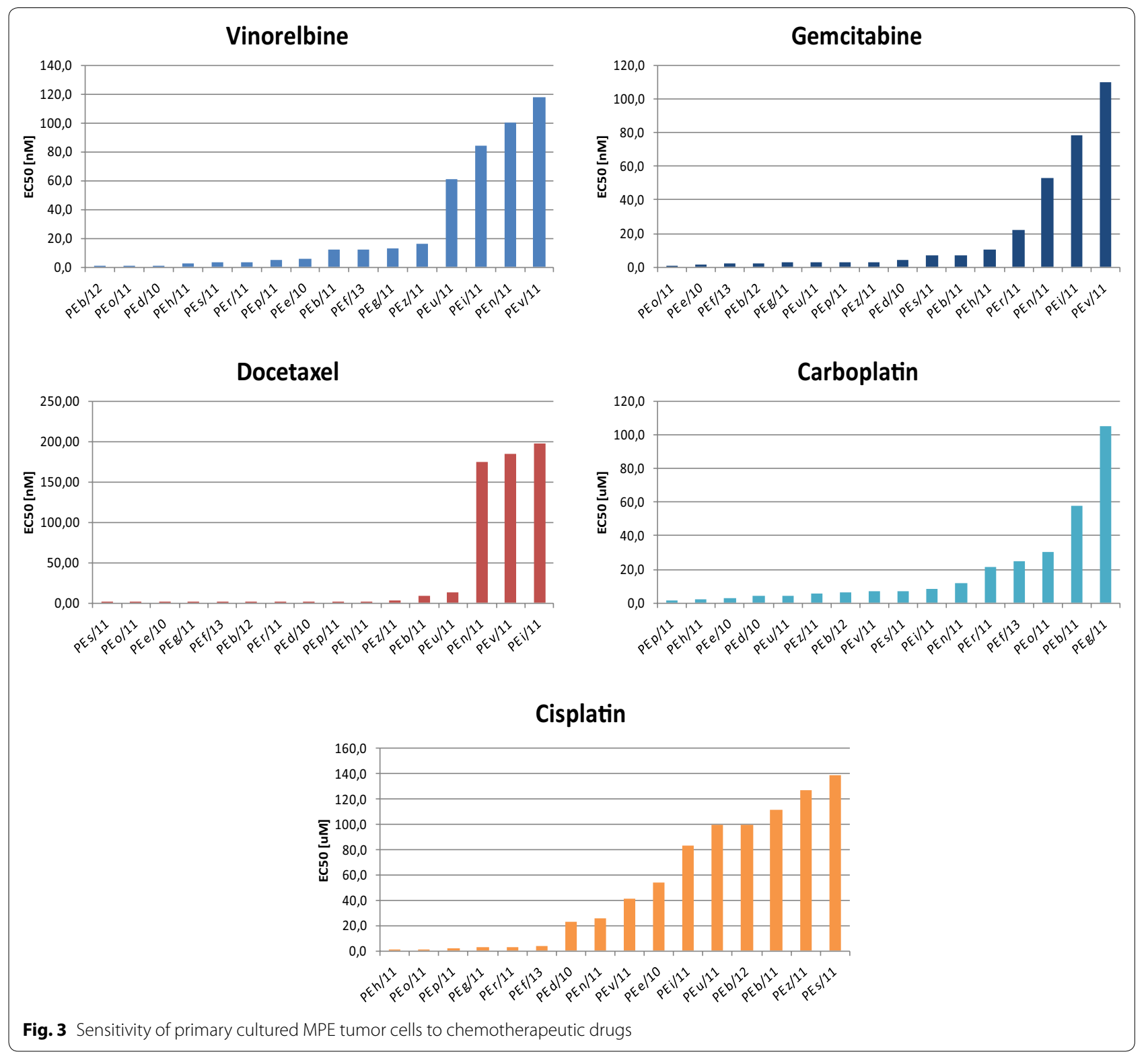


in terms of acquired resistance, usually show cross resistance [39-41]. Reduced sensitivity to cisplatin may reside in an active drug efflux, like Copper efflux systems [42, 43], that preferentially inhibits drug accumulation in the cells. Since several mechanisms of resistance to platinum-based compounds have been described [44], a final explanation cannot be provided without the execution of further studies.

In Fig. 4 is a heat map of single drug sensitivity to the five chemodrugs and to the two TKIs. This highlights that the two drugs for which there is a higher degree of sensitivity are gemcitabine and docetaxel. This is intriguing because these are usually not the first line treatment for this group of patients. Our findings therefore underscore the importance of this type of in vitro chemosensitivity studies to better instruct clinicians about the most efficacious therapy to use for this highly aggressive manifestation of disease.
In vitro assays lead to the identification of more effective synergistic combinations

Patients affected by NSCLC are usually treated with combination of drugs especially when diagnosed at late stage when there are no other treatment options $[45,46]$. MPE-derived cultures were assessed for their sensitivity to combination of drugs mostly used in the clinical settings and the results were evaluated by the Chou-Talalay method [47]. In Fig. 5a, b is shown as example the case of the MPE-derived $r / 11$, where a strong synergism between cisplatin and gemcitabine could be observed. We conducted a more systematic analysis of the combinatorial effect of vinolrebine, docetaxel and gemcitabine in 6 samples, $\mathrm{g} / 11, \mathrm{n} / 11, \mathrm{p} / 11, \mathrm{r} / 11, \mathrm{~s} / 11$ and $\mathrm{u} / 11$ and the results are reported in Table 3 . This analysis allowed to distinguish three distinct cases: additivity as in the case of $\mathrm{g} / 11$, antagonism in $\mathrm{n} / 11$ and $\mathrm{p} / 11$ and finally synergism in $\mathrm{r} / 11, \mathrm{~s} / 11$ and $\mathrm{u} / 11$.

\section{Vinorelbine Gemcitabine Docetaxel Gefitinib Erlotinib Carboplatin Cisplatin}

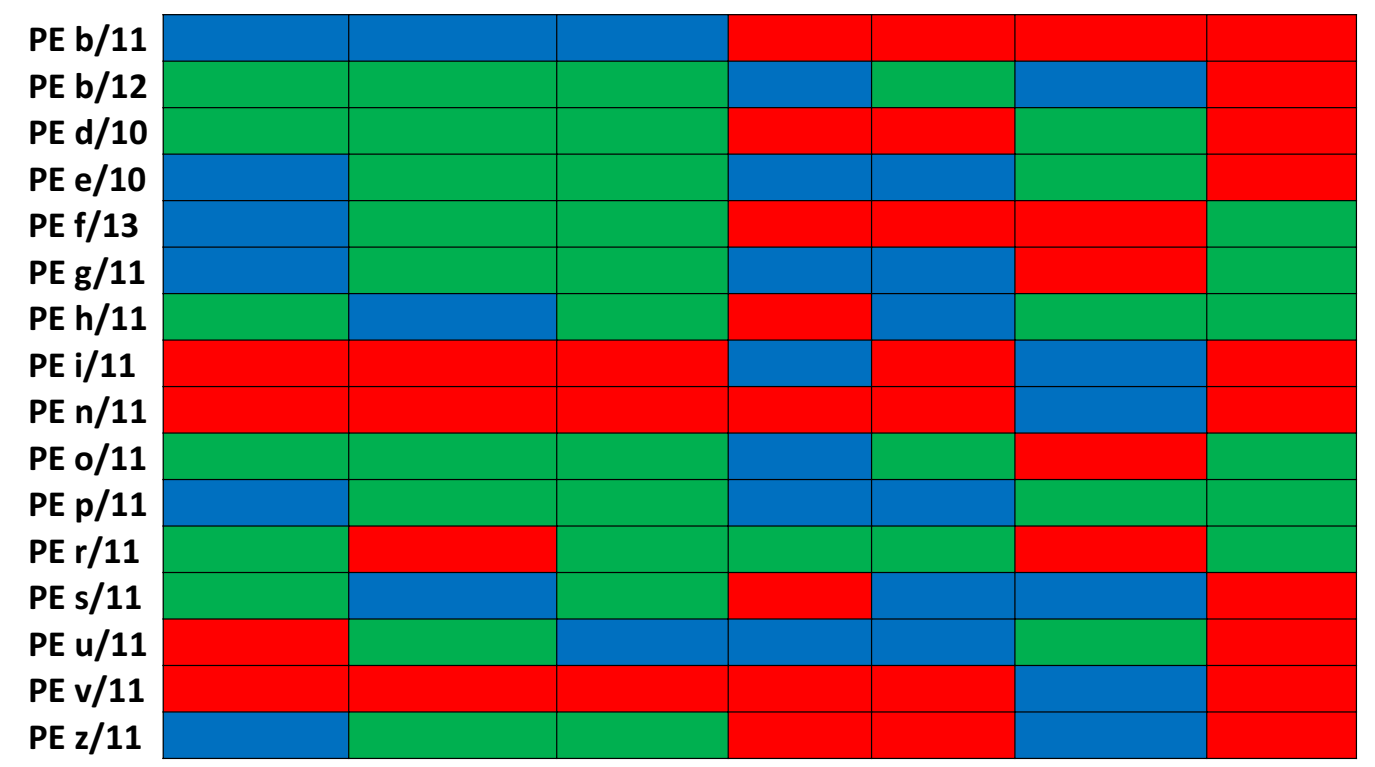

\begin{tabular}{l|c|c|c|}
\cline { 2 - 4 } Vinorelbine & $0-5 n M$ & $5-20 n M$ & $>20 n M$ \\
\cline { 2 - 4 } Gemcitabine & $0-5 n M$ & $5-20 n M$ & $>20 n M$ \\
\cline { 2 - 4 } $\begin{array}{l}\text { Docetaxel } \\
\text { Gefitinib }\end{array}$ & $0-5 n M$ & $5-20 n M$ & $>20 n M$ \\
\hline Erlotinib & $0-5 u M$ & $5-10 u M$ & $>10 u M$ \\
\hline Carboplatin & $0-5 u M$ & $5-10 u M$ & $>10 u M$ \\
\hline Cisplatin & $0-5 u M$ & $5-20 u M$ & $>20 u M$ \\
\hline
\end{tabular}

Fig. 4 Sensitivity heat map of PE primary cultures treated with single chemotherapeutic agent 


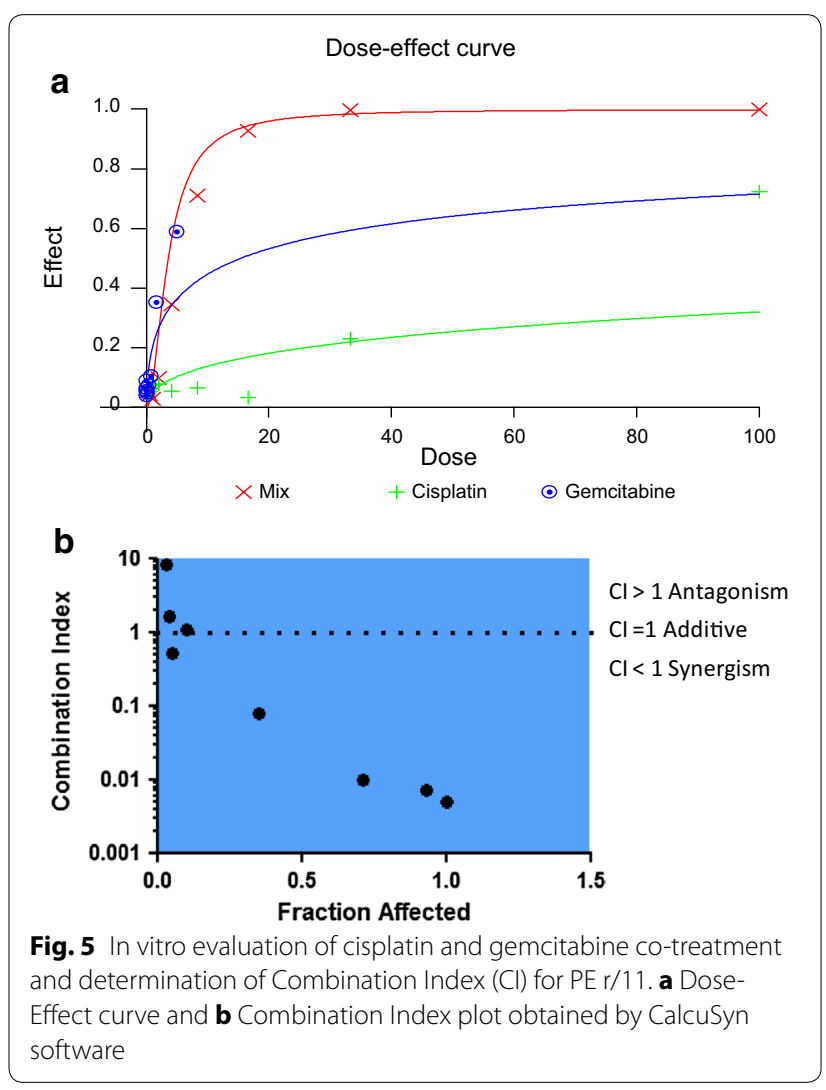

Table 3 In vitro determination of Combination Index (CI) of cisplatin combined with gemcitabine, or vinorelbine or taxotere

\begin{tabular}{lll}
\hline MPE culture & Cisplatin combination & Cl \\
\hline PE g/11 & Vinorelbine & 1 \\
& Gemcitabine & 1 \\
& Docetaxel & 1 \\
PE n/11 & Vinorelbine & $>1$ \\
& Gemcitabine & $>1$ \\
& Docetaxel & $>1$ \\
PE p/11 & Vinorelbine & $>1$ \\
& Gemcitabine & $>1$ \\
& Docetaxel & $<1$ \\
PE $/ 11$ & Vinorelbine & $<1$ \\
& Gemcitabine & $<1$ \\
PE $/ 11$ & Docetaxel & $<1$ \\
& Vinorelbine & $<1$ \\
& Gemcitabine & $<1$ \\
PE u/11 & Docetaxel & $<1$ \\
& Vinorelbine & $<1$ \\
& Gemcitabine & $<1$ \\
& Docetaxel & 1 \\
\hline
\end{tabular}

Therefore, we can conclude that MPE-derived cultures can be used to determine not only the degree of chemosensitivity to single drugs but also the degree of synergism to combinations of different chemotherapeutic agents.

\section{Correlation between in vitro drug sensitivity and in vivo response to therapy}

For six MPE-derived cultures for which we were able to assess in vitro chemosensitivity we had information about the first line therapy adopted and the clinical response. These data are shown in Table 4.

Two patients \#1 and \#2 from whom the g/11 and n/11 cultures were derived respectively, were treated with the combination of cisplatin and vinolrebine. Patient \#3 from whom p/11 was obtained, was treated with the combination of cisplatin and gemcitabine. Patients \#4 and \#6 from whom $\mathrm{r} / 11$ and $\mathrm{u} / 11$ were obtained were treated with the combination cisplatin + emcitabine +Bevacizumab. Finally patient \#5 from whom s/11 was obtained was treated with the combination of cisplatin plus Taxotere.

Patients, \#1, \#4, \#5 and \#6 developed a partial response. This nicely correlated with the in vitro sensitivity of the corresponding cultures to at least one of the drug used in single treatments, i.e., g/11 (patient \#1) to cisplatin; r/11 (patient \#4) to cisplatin; s/11 (patient \#5) to docetaxel, u/11 (patient \#6) to gemcitabine. Stable disease was observed in patient \#3 where the corresponding p/11 culture showed in vitro sensitivity to both agents used in therapy cisplatin and gemcitabine. Finally, patient \#2 underwent progressive disease upon treatment with cisplatin plus vinolrebine in line with the in vitro resistance of the corresponding $n / 11$ culture to both agents.

Although the number of the patients enrolled is low, it is intriguing to observe that in vitro chemosensitivity data match with clinical responses to therapy, which suggests that the use of MPE-derived cultures may be helpful to predict in the future the best treatment for NSCLC patients with malignant pleural effusions. To confirm the significance of the acquired data a larger study with the appropriate number of patients would be required.

\section{Conclusions}

Malignant pleural effusion (MPE) is an unfavorable complication of NSCLC. MPE severely restricts quality of life and has a poor prognosis. It is a metastatic manifestation of the disease caused by a combination of different processes such as inflammation, enhanced angiogenesis and vascular leakage. Response to therapies is usually poor because of relatively high tumor burden and chemoresistance. This last feature is linked to the presence of Cancer Stem Cells as we and others have shown in previous studies $[23,48,49]$. We believe that such an 
Table 4 Available patient data on response to drug treatment

\begin{tabular}{|c|c|c|c|c|c|c|}
\hline Patient & $\begin{array}{l}\text { Primary } \\
\text { culture }\end{array}$ & 1st line therapy & $\begin{array}{l}\text { 1st line response } \\
\text { ( } 3 \text { cycle) }\end{array}$ & $\begin{array}{l}\text { 1st line response } \\
\text { (6 cycle) }\end{array}$ & 2nd line therapy & $\begin{array}{l}\text { 2nd line response } \\
\text { ( } 3 \text { cycle) }\end{array}$ \\
\hline$\# 1$ & PE g/11 & $\mathrm{Cis}+\mathrm{Vin}$ & PR & SD & Erlotinib & PD \\
\hline \#2 & $\mathrm{PEn} / 11$ & Cis + Vin & PD & & & \\
\hline \#3 & $\mathrm{PE} p / 11$ & $\mathrm{Cis}+\mathrm{Gem}$ & SD & SD & Pemetrexed & PD \\
\hline$\# 4$ & $\mathrm{PE} r / 11$ & $\mathrm{Cis}+\mathrm{Gem}+\mathrm{Beva}$ & $P R$ & & & \\
\hline \#5 & $\mathrm{PE} s / 11$ & Cis + Taxotere & PR & & & \\
\hline \#6 & $\mathrm{PE} \mathrm{u} / 11$ & $\mathrm{Cis}+\mathrm{Gem}+$ Beva & PR & & & \\
\hline
\end{tabular}

Clinical response: $P D$ progression disease, $S D$ stable disease, $P R$ partial regression, $C R$ complete

aggressive disease requires a novel therapeutic strategy based on a personalized approach and that this should stem from the combination of genetic analysis of tumor cells as well as from accurate prediction of chemosensitivity. In this study we have demonstrated the possibility to expand an initial population of MPE-derived tumor cells both through short term primary cultures as well as xenografts in order to carry out chemosensitivity assay and genetic characterization for most commonly altered driver genes in NSCLC. Data obtained highlight the extreme genetic heterogeneity of this disease but also the possibility to identify in the majority of cases mutations in actionable genes. Therefore it should be possible to link this type of genetic characterization to patients' enrollment in umbrella clinical trials with novel targeted agents [50]. Limiting our analysis to more conventional chemotherapies, a more feasible and immediate application of our findings stems from the analysis of in vitro chemosensitivity of MPE-derived cultures. We show here that sensitivity to chemotherapeutic agents is highly heterogeneous. However we also show that it is possible in all cases to identify a combination of drugs that have a synergistic effect in inhibiting tumor growth and that this combination is often not the most frequent combination used in the clinic. Finally, although limited to a very small number of cases we show that in vitro chemosensitivity data match with patients' response to therapy in the clinic. We believe that streamlining MPE sample processing with in vitro chemosensitivity and genetic analysis by NGS could open up new therapeutic options for this group of patients currently with limited therapeutic options and short term life expectancy. However one has to take into account that MPEs are present only in a small subset of the patients with advanced lung cancer, are a negative prognostic factor and strongly correlate to short patients' survival. Thus, their clinical use could be limited by the extreme cancer burden and by the short life expectancy of patients. Therefore it would be of much greater clinical impact to translate our approach to primary lung tumors and to expand in vitro and/or in vivo the usually very small amount of material obtained from biopsies in order to be able to fully assess chemosensitivity.

\section{Additional files}

Additional file 1: Table S1. Whole genome exome sequencing. Analysis of sequence reads. Table S2. Doubling time and latency of MPE primary cultures in Rag2/II2rgamma double knock-out mice.

Additional file 2. Distribution in the chromosomes of the common nonsynonymous variants.

\section{Abbreviations}

MPE: malignant pleural effusion; NSCLC: non-small cell lung cancer; PDX: patient derived xenograft; CDX: cell line derived xenograft; CRD: clinically relevant doses; EMT: epithelial-to-mesenchimal transition; Cl: combination index; DT: doubling time; PD: progression disease; SD: stable disease; PR: partial regression; CR: complete regression.

\section{Authors' contributions}

GR coordinated most of the experimental work and contributed to manuscript writing; FFF carried out in vitro drug sensitivity and PDX studies; CDV, AN and EC generated and banked MPE-derived NSCLC primary cultures; AR and SM were the clinicians who obtained malignant pleural effusions from patients and established their chemotherapies; EG and MRG carried out and supervised diagnostic analysis of all primary cultures; MRT suggested some experiments; FB performed the functional and pathway analysis; SC performed bioinformatics analysis of whole exome sequencing data; FF and $M L$ carried out next generation sequencing by ion torrent; LA contributed to manuscript writing and revised the manuscript; NN supervised next generation sequencing by ion torrent and revised the manuscript; GC proposed several experiments and wrote large sections of the manuscript; RM supervised all the activities leading to generation, banking and characterization of MPEderived primary cultures, she also inspired the entire study and contributed to manuscript writing. All authors read and approved the final manuscript.

\section{Author details}

${ }^{1}$ Department of Clinical and Molecular Medicine, Sapienza University of Rome, Rome, Italy. ${ }^{2}$ Takis srl, Rome, Italy. ${ }^{3}$ Laboratory of Research and Diagnostics, Department of Surgery "P.Valdoni", Sapienza University of Rome, Rome, Italy. ${ }^{4}$ Azienda Ospedaliera S. Andrea, Rome, Italy. ${ }^{5}$ IRCCS Istituto Nazionale Tumori, Fondazione "G. Pascale", Naples, Italy.

\section{Acknowledgements}

This work was partially supported by AIRC Grants IG 10334 and 15216 to G. Ciliberto, by AIRC Grant IG 17009 to R. Mancini and by POR FESR Lazio 2007/2013 to R. Mancini and Takis s.r.l.

\section{Competing interests}

GR, FFF and LA: are employees of Takis s.r.l. Other authors declare that they have no competing interests. 
Received: 14 December 2015 Accepted: 13 February 2016 Published online: 29 February 2016

\section{References}

1. Siegel R, Naishadham D, Jemal A. Cancer statistics. CA Cancer J Clin. 2012;62(1):10-29.

2. Hoffman PC, Mauer AM, Vokes EE. Lung cancer. Lancet. 2000;355(9202):479-85.

3. Crystal AS, Shaw AT, Sequist LV, Friboulet L, Niederst MJ, Lockerman EL, et al. Patient-derived models of acquired resistance can identify effective drug combinations for cancer. Science. 2014;346(6216):1480-6.

4. Cufer T, Knez L. Update on systemic therapy of advanced non-small-cell lung cancer. Expert Rev Anticancer Ther. 2014;14(10):1189-203.

5. Gerber DE, Oxnard GR, Govindan R. ALCHEMIST: bringing genomic discovery and targeted therapies to early-stage lung cancer. Clin Pharmacol Ther. 2015;97(5):447-50

6. Rosell R, Karachaliou N. Lung cancer in 2014: optimizing lung cancer treatment approaches. Nat Rev Clin oncol. 2015;12(2):75-6.

7. Hyman DM, Solit DB. Tumor genetic screening programs: a call to action. J Clin Oncol. 2015;33(25):2725-6.

8. Cree IA, Kurbacher CM. Individualizing chemotherapy for solid tumors-is there any alternative? Anticancer Drugs. 1997;8(6):541-8.

9. Blumenthal RD, Goldenberg DM. Methods and goals for the use of in vitro and in vivo chemosensitivity testing. Mol Biotechnol. 2007;35(2):185-97.

10. Tentler JJ, Tan AC, Weekes CD, Jimeno A, Leong S, Pitts TM, et al. Patientderived tumour xenografts as models for oncology drug development. Nat Rev Clin Oncol. 2012;9(6):338-50.

11. Siolas D, Hannon GJ. Patient-derived tumor xenografts: transforming clinical samples into mouse models. Cancer Res. 2013;73(17):5315-9.

12. Hidalgo M, Amant F, Biankin AV, Budinska E, Byrne AT, Caldas C, et al. Patient-derived xenograft models: an emerging platform for translational cancer research. Cancer Discov. 2014;4(9):998-1013.

13. Ricci F, Bizzaro F, Cesca M, Guffanti F, Ganzinelli M, Decio A, et al. Patientderived ovarian tumor xenografts recapitulate human clinicopathology and genetic alterations. Cancer Res. 2014;74(23):6980-90.

14. Rosfjord E, Lucas J, Li G, Gerber HP. Advances in patient-derived tumor xenografts: from target identification to predicting clinical response rates in oncology. Biochem Pharmacol. 2014;91(2):135-43.

15. Sicklick JK, Leonard SY, Babicky ML, Tang CM, Mose ES, French RP, et al. Generation of orthotopic patient-derived xenografts from gastrointestinal stromal tumor. J Transl Med. 2014;12:41.

16. Marangoni E, Poupon MF. Patient-derived tumour xenografts as models for breast cancer drug development. Curr Opin Oncol. 2014;26(6):556-61.

17. Landis MD, Lehmann BD, Pietenpol JA, Chang JC. Patient-derived breast tumor xenografts facilitating personalized cancer therapy. Breast Cancer Res. 2013;15(1):201.

18. Kopetz S, Lemos R, Powis $G$. The promise of patient-derived xenografts: the best laid plans of mice and men. Clin Cancer Res. 2012;18(19):5160-2.

19. Ilie M, Nunes M, Blot L, Hofman V, Long-Mira E, Butori C, et al. Setting up a wide panel of patient-derived tumor xenografts of non-small cell lung cancer by improving the preanalytical steps. Cancer Med. 2015;4(2):201-11.

20. Fujii E, Kato A, Chen YJ, Matsubara K, Ohnishi Y, Suzuki M. The status of donor cancer tissues affects the fate of patient-derived colorectal cancer xenografts in NOG mice. Experimental Animals/Japanese Association for Laboratory Animal Science. 2015.

21. Stein AP, Saha S, Liu CZ, Hartig GK, Lambert PF, Kimple RJ. Influence of handling conditions on the establishment and propagation of head and neck cancer patient derived xenografts. PLoS ONE. 2014;9(6):e100995.

22. Lee HW, Lee JI, Lee SJ, Cho HJ, Song HJ, da Jeong E, et al. Patient-derived xenografts from non-small cell lung cancer brain metastases are valuable translational platforms for the development of personalized targeted therapy. Clin Cancer Res. 2015;21(5):1172-82.

23. Mancini R, Giarnieri E, De Vitis C, Malanga D, Roscilli G, Noto A, et al. Spheres derived from lung adenocarcinoma pleural effusions: molecular characterization and tumor engraftment. PLOS ONE. 2011;6(7):e21320.
24. Giarnieri E, De Vitis C, Noto A, Roscilli G, Salerno G, Mariotta S, et al. EMT markers in lung adenocarcinoma pleural effusion spheroid cells. J Cell Physiol. 2013;228(8):1720-6.

25. Noto A, De Vitis C, Roscilli G, Fattore L, Malpicci D, Marra E, et al. Combination therapy with anti-ErbB3 monoclonal antibodies and EGFR TKIs potently inhibits non-small cell lung cancer. Oncotarget. 2013;4(8):1253-65.

26. Ciardiello F, Normanno N, Maiello E, Martinelli E, Troiani T, Pisconti S, et al. Clinical activity of FOLFIRI plus cetuximab according to extended gene mutation status by next-generation sequencing: findings from the CAPRI-GOIM trial. Ann Oncol. 2014;25(9):1756-61.

27. Li H, Durbin R. Fast and accurate short read alignment with BurrowsWheeler transform. Bioinformatics. 2009;25(14):1754-60.

28. McKenna A, Hanna M, Banks E, Sivachenko A, Cibulskis K, Kernytsky A, et al. The genome analysis toolkit: a mapreduce framework for analyzing next-generation DNA sequencing data. Genome Res. 2010;20(9):1297-303.

29. Cancer Genome Atlas Research N. Comprehensive molecular profiling of lung adenocarcinoma. Nature. 2014;511(7511):543-50.

30. Smits AJ, Kummer JA, Hinrichs JW, Herder GJ, Scheidel-Jacobse KC, Jiwa $\mathrm{NM}$, et al. EGFR and KRAS mutations in lung carcinomas in the Dutch population: increased EGFR mutation frequency in malignant pleural effusion of lung adenocarcinoma. Cellular Oncol. 2012;35(3):189-96.

31. Yu HA, Arcila ME, Hellmann MD, Kris MG, Ladanyi M, Riely GJ. Poor response to erlotinib in patients with tumors containing baseline EGFR T790 M mutations found by routine clinical molecular testing. Ann Oncol. 2014;25(2):423-8.

32. Lee Y, Lee GK, Lee YS, Zhang W, Hwang JA, Nam BH, et al. Clinical outcome according to the level of preexisting epidermal growth factor receptor T790 M mutation in patients with lung cancer harboring sensitive epidermal growth factor receptor mutations. Cancer. 2014;120(14):2090-8.

33. Normanno N, Rachiglio AM, Lambiase M, Martinelli E, Fenizia F, Esposito C et al. Heterogeneity of KRAS, NRAS, BRAF and PIK3CA mutations in metastatic colorectal cancer and potential effects on therapy in the CAPRI GOIM trial. Ann Oncol 2015.

34. Sottoriva A, Kang H, Ma Z, Graham TA, Salomon MP, Zhao J, et al. A Big Bang model of human colorectal tumor growth. Nat Genet. 2015:47(3):209-16.

35. Zardavas D, Irrthum A, Swanton C, Piccart M. Clinical management of breast cancer heterogeneity. Nat Rev Clin Oncol. 2015.

36. Zhang J, Fujimoto J, Wedge DC, Song X, Seth S, Chow CW, et al. Intratumor heterogeneity in localized lung adenocarcinomas delineated by multiregion sequencing. Science. 2014;346(6206):256-9.

37. de Bruin EC, McGranahan N, Mitter R, Salm M, Wedge DC, Yates L, et al. Spatial and temporal diversity in genomic instability processes defines lung cancer evolution. Science. 2014;346(6206):251-6.

38. Ryu JS, Ryu HJ, Lee SN, Memon A, Lee SK, Nam HS, et al. Prognostic impact of minimal pleural effusion in non-small-cell lung cancer. J Clin Oncol. 2014;32(9):960-7.

39. Hamaguchi K, Godwin AK, Yakushiji M, O'Dwyer PJ, Ozols RF, Hamilton TC. Cross-resistance to diverse drugs is associated with primary cisplatin resistance in ovarian cancer cell lines. Cancer Res. 1993;53(21):5225-32.

40. Oliver TG, Mercer KL, Sayles LC, Burke JR, Mendus D, Lovejoy KS, et al. Chronic cisplatin treatment promotes enhanced damage repair and tumor progression in a mouse model of lung cancer. Genes Dev. 2010;24(8):837-52.

41. Galluzzi L, Vitale I, Michels J, Brenner C, Szabadkai G, Harel-Bellan A, et al. Systems biology of cisplatin resistance: past, present and future. Cell Death Dis. 2014;5:e1257.

42. Yoshizawa K, Nozaki S, Kitahara H, Ohara T, Kato K, Kawashiri S, et al. Copper efflux transporter (ATP7B) contributes to the acquisition of cisplatin-resistance in human oral squamous cell lines. Oncol Rep. 2007;18(4):987-91.

43. Safaei R, Otani S, Larson BJ, Rasmussen ML, Howell SB. Transport of cisplatin by the copper efflux transporter ATP7B. Mol Pharmacol. 2008;73(2):461-8.

44. Shen DW, Pouliot LM, Hall MD, Gottesman MM. Cisplatin resistance: a cellular self-defense mechanism resulting from multiple epigenetic and genetic changes. Pharmacol Rev. 2012;64(3):706-21. 
45. Carnio S, Novello S, Mele T, Levra MG, Scagliotti GV. Extending survival of stage IV non-small cell lung cancer. Semin Oncol. 2014;41(1):69-92.

46. Scheff RJ, Schneider BJ. Non-small-cell lung cancer: treatment of late stage disease: chemotherapeutics and new frontiers. Semin Intervent Radiol. 2013;30(2):191-8.

47. Chou TC. Drug combination studies and their synergy quantification using the Chou-Talalay method. Cancer Res. 2010;70(2):440-6.

48. Ricci-Vitiani L, Lombardi DG, Pilozzi E, Biffoni M, Todaro M, Peschle C, et al. Identification and expansion of human colon-cancer-initiating cells. Nature. 2007;445(7123):111-5.
49. Dontu G, Al-Hajj M, Abdallah WM, Clarke MF, Wicha MS. Stem cells in normal breast development and breast cancer. Cell Prolif. 2003;36(Suppl 1):59-72.

50. Meric-Bernstam F, Brusco L, Shaw K, Horombe C, Kopetz S, Davies MA, et al. Feasibility of large-scale genomic testing to facilitate enrollment onto genomically matched clinical trials. J Clin Oncol. 2015;33(25):2753-62.
Submit your next manuscript to BioMed Central and we will help you at every step:

- We accept pre-submission inquiries

- Our selector tool helps you to find the most relevant journal

- We provide round the clock customer support

- Convenient online submission

- Thorough peer review

- Inclusion in PubMed and all major indexing services

- Maximum visibility for your research

Submit your manuscript at www.biomedcentral.com/submit
() Biomed Central 